\title{
Narrate It Until You Become It
}

\begin{abstract}
Research in phenomenology and philosophy of psychiatry has suggested that psychopathological disturbances of experience often involve an alteration of one's 'sense of possibility', dependent upon the presence of specific 'existential feelings' (Ratcliffe 20I2). In this paper I provide an extended account of how the engagement with certain narratives can lead to a transformation of one's sense of possibility by eliciting affective experiences that are not consonant with the person's existential feelings. More precisely, I claim that, even when the experience of some types of emotion is generally precluded by a restricted sense of possibility, such emotions may be aroused by particular self-narratives, and I explore how this dynamic can give rise to enduring and wide-ranging affective changes.
\end{abstract}

KEYWORDS: existential feelings, sense of possibility, narrative, self, mental health

\section{Introduction}

In contemporary phenomenology and philosophy of psychiatry it has been claimed that various forms of mental illness involve an alteration of the person's 'sense of possibility' (Ratcliffe 20I2: 28). More specifically, it has been suggested that a person's sense of what is possible for her to experience or achieve is in these cases dramatically restricted (e.g., Fuchs 2007; Ratcliffe 2008, 20I5; Slaby 20I2), a dynamic that has been shown to be closely related to the presence of certain disturbances of affectivity (e.g., Bortolan 20I7; Ratcliffe 2008, 20I5). In particular, attention has been drawn to the role that a specific type of background affective orientations-which Matthew Ratcliffe has identified and described through the notion of 'existential feelings' (e.g., 2005, 2008)-plays in this context. Existential feelings are conceived as a particular set of bodily feelings that are not directed at any particular object, but are rather experiences of one's relationship with the world as a whole, and it is claimed that the sense of possibility fundamentally impinges upon them.

Ratcliffe's work provides numerous illustrations of how alterations of existential feelings and related affective experiences may have a plurality of effects, for example, affecting the person's motivation, experience of time, and social perception and interaction (e.g. Ratcliffe 20I5). The disturbances of affectivity at issue have also been argued to have the potential to influence the way in which the person conceives of herself and her story-her narrative self-understanding-limiting or distorting it in various ways (Bortolan 20I7; Ratcliffe 20I6). This is of particular importance because narrativity has been conceived as being closely related not only to a 
particular form of self-consciousness, but also to the constitution of the self, or a specific aspect of it (e.g., Bruner 2002; Zahavi 2005). As such, alterations of this dimension have to be seen as significant threats to the integrity of the person's mental and practical life.

The elaboration and modification of certain self-narratives has also been seen as a central aspect of treatment and recovery processes (Bortolan 2020a; Pickard 20I 5), and as something that may have the power to trigger enduring affective transformations. This is the idea at the core of various narrative approaches to psychotherapy (Angus and Greenberg 20II; Payne 2006), where emphasis has been placed on the role played by narratives in self-regulation and on how changes in the way in which one's life stories are conceived and recounted can have wide-ranging effects on mental health.

The aim of this paper is to contribute to research on the role of narrative self-understanding in the recovery from mental ill-health through the investigation of the ways in which narratives can contribute to restore and expand one's sense of possibility. I argue that the engagement with self-narratives of a certain kind can lead to transformations of existential feelings in virtue of the ability of these narratives to trigger the experience of emotions that are not consonant with the person's background affective orientations, a shift that has the potential to lead to more enduring cognitive and affective changes.

To support my point, I draw on research by Noël Carroll on the affective relationship between the audience and the characters of fictional works (200I, 20I I). I maintain that there is a parallel between the way in which we relate to fictional characters in a story and the way in which we respond to ourselves as the protagonists of our self-narratives. Expanding on my previous research on the topic (Bortolan 2020b), I provide an extended account of the relevant dynamics. To be more precise, I claim that even when a restricted sense of possibility makes it difficult to experience certain emotions in relation to ourselves, the ability to engage affectively with fictional characters may enable the experience of these emotions in response to particular self-narratives, paving the way to broader modifications of one's existential feelings and sense of possibility. As such, engaging with certain self-narratives can contribute to broadening one's affective repertoire, making it possible for the experiences of the narrator to become more similar to the experiences of their narrated self. ${ }^{\mathrm{I}}$

\section{Affects and Possibility}

In the phenomenological literature a connection has been established between certain forms of affective experience and the possibility space we inhabit-namely, what it is possible for us to experience and what we experience as possible.

\footnotetext{
I The title of this article seeks to capture this dynamic through a play on the phrase 'fake it until you make it'; more precisely, it is loosely inspired by a passage in a talk by Amy Cuddy (20I 2) in which the expression 'fake it till you become it' is used. Cuddy's talk focuses on the effects that changes in one's body language and behavior can have on one's performances and self-understanding, while here my concern is with the relationship between narrativity, affectivity, and self-experience. Nevertheless, the emphasis on the transformational role of certain practices highlighted also by the use of the verb 'to become' is what my title aims to echo.
} 
A notion that is closely related to this question is that of 'existential feelings', which is inspired by classical phenomenological research on 'moods' (Heidegger I962). Within this framework, attention has been drawn to the fact that the ability to entertain intentional states is rooted in the experience of particular affects with a non-intentional structure (cf. Ratcliffe 2008: $47 \mathrm{ff} . ; 20 \mathrm{I}_{3} \mathrm{~b}$ ). In other terms, it has been suggested that cognitive, emotional, or volitional states directed at particular objects stem from a specific type of object-less affective experience. In the work of Heidegger this experience is characterized through the notion of 'moods', namely, ways of being 'attuned' or 'situated' in the world that make it possible for us to encounter things as significant in certain manners, enabling specific sets of affective responses (cf. Elpidorou and Freeman 2015; Ratcliffe $\left.20 \mathrm{I}_{3} \mathrm{~b}\right)$. From this perspective, moods are not conceived as 'inner' mental states that only occasionally come to color our experience; rather, they are viewed as ways of relating to the world that are constantly present and cannot be done without (Elpidorou and Freeman 20I 5: 664; Ratcliffe 2008).

Ratcliffe's notion of existential feeling has various aspects in common with Heidegger's concept of mood. One of the key features of existential feelings is indeed that they shape our experience by enabling things to matter to us in characteristic ways (Ratcliffe 2005, 2008, 20I2). In other terms, existential feelings modulate what 'kinds of significance' can be experienced by us (Ratcliffe 20IO): they are 'presupposed spaces of experiential possibility' (Ratcliffe 2005: 45) that enable us to perceive ourselves, other people, and the world as salient in various ways. Like Heideggerian moods, existential feelings do not have specific intentional objects, but rather determine 'what kinds of intentional state it is possible to have' (Ratcliffe 20I0: 604). On this account, Ratcliffe suggests that existential feelings have a 'pre-intentional' rather than a merely non-intentional structure: they constrain the range of intentional states we can undergo. This means that, depending on the particular existential feeling(s) we are experiencing, there will be certain thoughts, emotions, and desires that we have the possibility to entertain and others that will be precluded to us.

A very telling example offered by Ratcliffe concerns (existential) feelings of hopelessness (2013a). According to Ratcliffe's account, we can distinguish between intentional and pre-intentional forms of loss of hope. Often, losing hope entails losing hope with regard to particular possibilities (e.g., that one will achieve something or that a particular event will take place) (Ratcliffe 2013a: 599-600). In these cases, hopelessness is a feeling with a particular intentional structure. However, Ratcliffe observes that in certain circumstances-for example, in certain instances of severe depression (Ratcliffe 2013a: 605 ff.) - the loss of hope may have a deeper and wide-ranging character. Here the feeling of hopelessness is no longer directed to particular possibilities, but rather is to be understood as the 'loss of the capacity for hope' itself. This is an existential feeling as it does not have an intentional structure, but it constrains the set of intentional states that one can undergo. When in the grip of existential hopelessness, the experience of feelings of hope directed at particular possibilities is precluded to the person.

While existential feelings can have such a dramatic impact on one's experiences, it is important to note that they are not an all-or-nothing phenomenon, so to speak. For 
example, one may lose the capacity to hope for oneself, but still be able to feel hopeful about other people's prospects. In other terms, existential feelings have different degrees of 'depth' (Ratcliffe 20IO), depending on how extensive the range of possibilities that they open up or close down is.

Background affects like moods and existential feelings are thus attributed a key role in our mental and practical life, and this is highlighted also by their centrality to various psychiatric disturbances (Ratcliffe 2008, 2015). Given this, it is important to understand how such forms of affective experience can be regulated: are we in control of our moods and existential feelings? And if so, what are the means through which these states can be modulated? In other terms: can we change the background affective orientations that have the power to shape our sense of possibility in the ways described above?

The phenomenological literature does not provide us with a clear account of how this may happen. We know that moods and existential feelings change, thus modifying the possibility space we inhabit, but it is unclear whether and how we can regulate these experiences.

Heideggerian moods are not states that can be controlled through cognition and volition alone. A mood, Heidegger suggests, can be mastered by means of a 'countermood' (I962: I75), thus drawing attention to how the modification of our background affective orientations depends on the emergence of other states of the same kind. As explained by Guignon, 'I can only overcome my fearfulness . . by fixing myself in a mood of equanimity or indifference' (2003: 187).

This may suggest that we are rather powerless in the face of our moods and existential feelings. If these are affects that constrain the range of intentional states we can entertain and can only be swept away by affects of the same type, then it would seem that thoughts, emotions, and desires-due to intentionality being an essential aspect of their structure-would not by themselves have the power to change our background affective orientations.

However, it is also recognized that sometimes it is possible to undergo intentional states that trigger processes that can result in the transformation of the moods or existential feelings that are in the background of the intentional states themselves. An expression of this idea can be found in Stephan Strasser's work on moods. As he explains:

One can take as a theoretical model the image of a fountain. The water in the basin forms a unitary, undifferentiated mass; it would be comparable to the formless state of mind. The fluid is then divided into jets and ejected in different directions; the jets are-in Husserl, Scheler and Pfänder-an image of the separate and directed intentional performances. The finely atomized drops of water sink back unnoticed into the basin: this process would be comparable to the self-mixing, self-obliterating and self-canceling of experience. (Strasser I977: I8687)

The idea that, despite being radically shaped by our background affective orientations, intentional states can also influence such orientations emerges clearly 
also from Ratcliffe's own work. As he highlights: 'in some cases, an intentional state with content $p$ affects existential feeling $q$ in such a way as to remove the conditions of intelligibility for intentional states of that type' (Ratcliffe 2015: I 5I).

The question that is immediately raised by these claims concerns the ways in which intentional states can exert such an influence on the pre-intentional ones in which they are rooted. This is explicitly considered by Ratcliffe, who suggests that the answer may not fall within the remit of a phenomenological account. In his words:

But how could an intentional state somehow 'act upon' its own conditions of intelligibility? It is not clear to me that much more can be said from a phenomenological perspective-it simply happens, just as existential changes can happen when one is sick, tired or intoxicated. Perhaps, at this point, we need to switch to a non-phenomenological approach. For instance, there is a neurobiological story to be told. (2015: I 5 I)

I agree with Ratcliffe that an account of these dynamics may exceed the boundaries of phenomenology and that we should investigate, for instance, the neurobiological processes that underlie existential transformations. However, I also believe that it is possible to expand our phenomenological understanding, offering a finer-grained account of how such transformations are triggered and how they may unfold over time. In particular, it would be fruitful to clarify both which intentional states are relevant in this context and the processes through which experiencing them can engender existential changes.

The next sections of this paper will aim to shed light on these questions by exploring the role that intentional states like emotions may play in this context. Here I will investigate how one may come to experience emotions that are in contrast with existing background affective orientations and how these may trigger changes that have the capacity to modify one's existential feelings themselves.

\section{The Role of Narratives}

Emotions have been argued to be able to influence in fundamental ways the stories we tell about ourselves; on the other hand, a certain type of engagement with certain self-narratives has been seen as having an impact on emotion regulation. These ideas, for instance, are the core of the theoretical and methodological framework of a narrative approach to emotion-focused therapy (EFT; Angus and Greenberg 20II). Within this framework, it is acknowledged that self-narratives are rooted in the experience of certain feelings and that the modification of such narratives can feed back into affective experience, a dynamic that is seen as central to the processes through which positive transformations can be promoted. Outlining the 'dialectical constructivist model' of therapeutic change at the core of this approach, Greenberg and Angus highlight the mutual, recurrent influence between the relevant levels of self-experience: 
The self is viewed as a multiprocess, multilevel organization emerging from the dialectical interaction between ongoing, moment-by-moment experience and higher-level reflexive processes that attempt to interpret, order, and explain elementary experiential processes. In this view, affectively toned, preverbal, preconscious processing is seen as the major source of self experience. Articulating, organizing, and ordering this experience into a coherent narrative is the other major element. (2004: 332)

However, there are some problems that may be faced when we think of narratives as the potential means for the transformation of our background affective orientations. The particular moods or existential feelings we experience seem indeed able to shape in important ways also our narrative self-understanding. As I argued elsewhere (Bortolan 20I7), due to their pre-intentional structure, existential feelings can modulate both the form and contents of the autobiographical narratives we construct, leading us to create life stories that are consonant with the background affects we experience.

Ratcliffe himself recognizes that narratives can be integral to the structure of existential feelings (2016: I 80). For example, as previously mentioned, in the case of severe depression a loss of hope that things could ever be different may be experienced. As a result, Ratcliffe claims, the depressed person is unable to conceive of alternative self-interpretations, and her autobiographical stories lack 'narrative openness'(2016: I 84). In addition, on the basis of an examination of first-person accounts of grief, Ratcliffe maintains that certain alterations of existential feelings-involving, for example, disruptions of the way in which temporality is experienced-can even make it impossible to engage in the construction of autobiographical narratives (2016: I 84).

One could thus wonder whether the impact narratives can have on affects is limited to changing some of the emotions that are allowed for by certain existential feelings, rather than changing the existential feelings themselves. If we consider an existential form of hopelessness, for example, this would entail that a narrative could influence which of the emotions compatible with this background orientation are undergone-for instance, sadness, resignation, or dejection-but it would not have any power over hopelessness itself.

However, narrative therapy and the role of narrative changes in the recovery from psychiatric illness (Bortolan 2020a) suggest a different picture. 'Narrative-informed' EFT, for example, can be used in the treatment of depression (cf. Angus and Greenberg 20II), the overcoming of which requires a broadening of one's sense of possibility and thus a transformation of existential feelings.

In light of this and of the inextricability of affects and story-telling previously discussed, it may be expected that the narratives themselves can have an impact on moods and existential feelings. In other words, while background affective orientations incline us toward the construction of certain stories, it is arguable that stories, too, can exert an influence on the affective grounds from which they stem. In the following section I will illustrate the dynamics through which this can happen. 


\section{Self-Narratives and Fictional Narratives}

As outlined above, some phenomenologists have suggested that the experience of particular intentional states may lead to a modification of one's moods or existential feelings. It remains to be clarified, however, what the processes are through which both the intentional states and the changes may be brought about.

My working hypothesis is that this is possible in virtue of the emotional responses that are triggered by narratives, in particular by self-narratives, and the way in which these are subsequently cognitively and intersubjectively elaborated. I adopt here a characterization of emotions as states that possess both intentionality and a distinct phenomenology (Slaby 2008). Before further exploring this point, however, it is important to clarify what kind of narratives I have in mind, especially as a wide range of definitions of this notion has been given (see, e.g,. Goldie 2012; Lamarque 2004; Schechtman 2007; Slors I998).

Here I adopt a rather minimal account, considering as a self-narrative one that focuses on events that involve the narrator, a narrative 'that can be told or narrated, or just thought through in narrative thinking' (Goldie 20I2: 2). Such narratives can cover different time spans, focusing on events that take place over the course of years, months, or just a few minutes. The stories that are relevant here, therefore, are not necessarily those that report the events of an entire lifetime or that span significant periods of it. On the contrary, they can focus on circumscribed or isolated episodes, and these may be located at different points in time. For example, a narrative may report a past event, describe a present situation, or anticipate something that will happen in the future.

Given my interest in the relationship between narrativity and one's sense of possibility and the relevance of both to psychiatric illness, treatment, and recovery, in this context I am particularly interested in narratives that provide an account or interpretation of the recounted events in a way that challenges or is alternative to the person's prior or predominant views (Bortolan 202ob: 200). For example, these can be narratives about past events that offer an evaluation of them that is different from the interpretation generally given by the person. A past event in which the person has been involved can, for instance, be renarrated not as a personal failure, but rather as something that was determined by circumstances beyond one's control or as a situation that involved a temporary set-back but is a positive, successful experience in the long term. Alternatively, the relevant narratives can be future-focused and include experiences and evaluations that would be precluded by one's current predicament. More broadly, the narratives relevant in this context may involve imagined events. For example, for a person who experiences pervasive feelings of worthlessness and hopelessness, a relevant narrative may involve imagining herself to be in circumstances in which she achieves something of value to her and feels empowered.

In order to shed light on the emotional effects that engaging in the construction and modification of self-narratives may have, it is helpful to consider the way in which we can respond affectively to stories more broadly. It is plausible that some 
of the key dynamics would be the same or similar in the case of narrativity and self-narrativity more specifically.

Research in philosophy of emotion and aesthetics has identified various forms of affective relation between the audience and the characters of the stories they engage with. With regard to the characters of popular fictions, Carroll (20I I), for example, has put forward a classification that includes the following categories: identification, coincident emotional states, vectorially converging emotive states, sympathy, solidarity, and mirror reflexes. Developing my previous research on the topic (Bortolan 2020b), in the following I will explore the similarities between the affective responses to fictional characters discussed by Carroll and the way in which we can relate to ourselves as the main characters of our life stories. I will suggest that this explains why engaging in narrative activities can trigger a process of affective transformation.

My focus will be on cases in which one's sense of possibility is altered in ways that preclude the experience of certain emotions in relation to oneself but not in relation to others or preclude certain types of emotion but not others. In particular, the processes I will discuss presuppose the capacity to affectively respond to fictional characters even when the range of self-focused emotions that one can entertain is radically restricted.

One could wonder, as a result, how significant such an account might be, as it could be claimed that the deepest alterations of one's sense of possibility involve the incapacity to experience kinds of emotion-for example, hope, excitement, or trust-independently of whether these are directed to fictional or real persons, to oneself or others. In other terms, one might object that we must be able to explain how someone who has lost the capacity to hope not only for herself, but for anyone and anything, can overcome this predicament and be hopeful again.

In response to this potential concern, I wish to highlight two things. First, the complete loss of the capacity to experience a particular kind of emotion is a comparatively rare event. Often, the transformations of experience engendered by the presence of a certain existential feeling are more circumscribed, and these cases are the ones that my account has the potential to shed light on. Second, even when one has lost the ability to undergo specific kinds of emotions, it might still be possible to experience other emotions of the same valence. The loss of the capacity to hope, for example, may be incompatible with some positive emotions - such as excitement or relief-but not with all of them. For instance, one may be unable to hope while still being capable of feeling love or gratitude toward others. This residual capacity for emotional resonance is what is leveraged in the narrative activities that are the focus of this paper, thus making the analysis developed here relevant to a diverse range of experiential configurations.

\section{I Carroll's Account and Responding to Oneself as the Protagonist of a Self-Narrative}

The first form of affective relationship between the audience and the characters of fictional works discussed by Carroll in the main text I am considering is 
identification or the 'infection model' (201 I: I67). By this, Carroll refers to cases in which the audience experiences the same emotion as a character in the story, and the cause of this experience is the fact that the character experiences such an emotion. For example, a character may be feeling happy or sad, and we feel happy or sad because of the character's own experience.

In the cases at issue here, there is a causal connection between the emotional experience of the character and the emotional experience of the audience; however, it is difficult to determine what might make this connection possible. Carroll tells us that in identification the audience is taken to undergo an emotion that is type-identical with the emotion of the character and that the latter is that in virtue of which the former is brought about. He acknowledges that mirror reflexes might play a role in eliciting these responses, but this can only provide a partial explanation, as only certain aspects of the emotion are shared through mirror reflexes (20II: I67, I77ff.). A broader explanation, however, can be given by drawing on the notion of identification itself, expanding the role it plays in accounting for the type of circumstances that Carroll discusses.

As highlighted above, the form of identification that Carroll refers to is emotional identification. This amounts to the audience's experiencing an emotion of the same type as the emotion experienced by the character because the character experiences it. As such, the identification in question concerns mental states and not individuals. However, it can be argued that in order for the emotion of the character to be the cause of a type-identical emotion in the audience, another form of identification should be in place. More specifically, the audience should be identifying with the character. It seems indeed plausible that it is because the audience, albeit briefly, takes the perspective of the character or puts themselves in their shoes, so to speak, that the emotion of the character can be the cause of the emergence of the same emotion in the audience.

Carroll (200I) traces this view back to Plato, with whom he disagrees, as he suggests that ' $\mathrm{r}$ ] ather than character identification, it is our own preexisting emotional constitution. . . that accounts for our emotional involvement with narrative fictions' (228). When spelling out different possible meanings of the notion of 'identification', Carroll mentions that the notion of identification as 'perspective-taking' differs from that of emotional identification (201 I: I66), and he expresses doubts concerning the extent to which it is really possible to take the perspective of another, rather than simply projecting one's perspective onto them. I agree with Carroll with regard to both points: identification (as perspective-taking) is different from emotional identification, and the former can involve a significant degree of projection. However, I believe that an audience's ability to emotionally identify with a character (in the way outlined by Carroll) depends on the audience having preliminarily identified with/taken the perspective of the character (even if this involves projection).

Carroll acknowledges that the idea that there can be a form of emotional identification between audiences and fictional characters has been very popular. However, he is skeptical about the generalizability of this account as, in his opinion, once we dissect the specific dynamics that are in play in these cases, a different picture emerges. More specifically, Carroll doubts that the character's 
emotions are always the cause of the audience's emotion and that the audience's emotions tend to be type-identical with the emotions of the characters (201 I: I $67 \mathrm{ff}$.).

Coincident emotional states are the second form of relationship between the audience and fictional characters identified by Carroll (20II: I69-7I). He characterizes these as emotional responses that are analogous to the emotions undergone by the characters and are motivated by a description of the characters' circumstances that emphasizes specific aspects. In these cases, the audience experiences an emotion not because the character experiences it, but rather because the features of the situation that are stressed in the narrative 'are those that are criterially apposite to the emotional states intended to be excited by the work', a dynamic Carroll refers to as 'criterial prefocussing' (200I: 227ff.; 20I I: I69). As an example of this he considers a narrative featuring the possibility of an atomic conflict. The president of the United States who features in this narrative is anxious and so is the audience. Carroll suggests that-contrary to what would be maintained by the infection model-the audience is not anxious because the president is in such emotional state, but rather in virtue of the circumstances that have been described as marked by various anxiety-eliciting features (e.g., mention of jet bombers and their damaging potential, difficult diplomatic relationships, etc.) (20I I: I69ff.).

While in coincident emotional states the audience and fictional character experience an emotion of the same type, in vectorially converging emotive statesthe third set of cases discussed by Carroll (20II: I7I-72)-the audience and the character experience emotions that have similar valence but are not of the same type. In these cases, the emotional state of the audience is experienced in response to one of the emotional states of the character herself, and contrary to the case of coincident emotional states, it is not a response to the described circumstances. As an example, we can consider a character who is feeling grief because of the death of a dear one and an audience who feels sad for her. The emotions at issue here, grief and sadness respectively, are both negatively valenced, and one is a reaction to the other, but they are instances of different types of emotion. To put this differently, in this type of affective relation the emotion of the audience is a response to the emotion of the character, and the two 'converge vectorially' in the same direction of the affective spectrum (Carroll 20II: I7I-72).

Sympathy and solidarity are more complex ways in which an audience can relate affectively to the characters of fictional works. Sympathy is defined by Carroll as an emotional state motivated by 'a non-passing pro-attitude' or a form of caring integral to which is the desire that 'things work out well' for the person to whom sympathy is directed (20II: I73). This inclines the audience to experience affects that are not necessarily aligned with the affects of the character. For instance, the character may be happy about something that happens to her, but as the audience fears some unpredicted consequences or is in possession of information unknown to the character, the audience is concerned or sad about how the character may be affected by the event in question. According to Carroll, sympathy is experienced if the person it is directed to is appraised as being 'worthy of our emotions', something that is achieved in popular fiction through a depiction of the character as 'morally good' (20II: I74), while in real life sympathy tends to be extended 'quite readily to most of those around us by default' (20II: I76). Sympathy is conceived as an essential aspect 
of solidarity, a way of relating to multiple characters that involves both 'sympathy-forthe-protagonists' and 'antipathy-for-the-antagonists' (20I I: I76).

The last form of affective relation between the audience and fictional characters considered by Carroll is what he discusses under the heading of mirror reflexes (20I I: I77-80). Carroll's account here relies on the acknowledgment that we tend to imitate both the facial expressions and postures of real people as well as of fictional characters (20II: I78). Such imitative responses, as Carroll notes, are not full-blown emotions, but may be constitutive parts of them, as certain bodily, expressive, and postural changes are integral aspects of specific affective reactions. On this basis, Carroll suggests that the dynamics triggered by these tendencies can contribute to our understanding of other people's emotions, and provide the grounds for relevant emotional responses. This is relevant to the understanding of the affective reactions we experience when we watch or hear someone; thus, it applies to audiovisual narratives, for example, in films and theatrical performances. However, it has been shown that 'overlapping neural areas' tend to be activated when certain actions are performed, observed, and also when they are simply imagined (cf. Gallagher and Zahavi 2012: I98), and this would be compatible with the dynamics considered by Carroll being in place also in the case of narratives that are only engaged with in imaginative thinking.

The affective reactions listed by Carroll are undergone by an audience in response to the emotions experienced by fictional characters or to their circumstances. As such, Carroll is concerned primarily with cases in which the protagonists and audiences of a story do not coincide. However, it is arguable that some of these dynamics may be in play also when the characters in the story are not fictional and, more specifically, when the narrator and the protagonist coincide as is the case in self-narratives. That is, there may be a parallel between some of the ways in which we relate to the characters in fictional narratives and the way in which we relate to ourselves as the main characters in our own narratives (Bortolan 2020b: 200-20I). If this is the case, provided that we have retained the capacity to undergo certain types of emotional response to fictional characters, engaging in self-focused forms of story-telling may be a way to trigger emotions and other intentional states involved in the transformation of one's background affective orientations.

In order to illustrate how this may be the case, let us consider what may happen when a person who feels radically powerless, hopeless, and lacking in self-confidence - whether in a therapeutic or other setting-engages in the construction of a narrative involving experiences and events that appear to be largely unattainable given the person's existing affective orientation. As highlighted previously, the story-telling in question may involve a past event that is given a different interpretation, or it may focus on a present or future possible scenario. For example, the person may be prompted to retell the story of a past performance that she considered as an example of her inability to do anything good, and she may retell it as a story in which something of value was achieved. Or the person may simply imagine a new story, not related to a past event but having a connection with her life circumstances, in which she does something valuable-for instance, she gives a good talk at a public event, wins a sports competition, or successfully campaigns in support of a moral cause important to her. 
While not all forms of affective relation to fictional characters highlighted above may be available to the person who engages in the construction or communication of such a self-narrative, my suggestion is that some of them will, and this may be the starting point for the affective transformation that may lead to expand the person's sense of possibility. Thus, the narrative with oneself as the protagonist will be able to trigger various forms of affective response, much like a fictional narrative does, and this may start the process that will lead to the modification of the background affective orientation.

Let us consider emotional identification first. As highlighted above, this is how Carroll characterizes the view according to which the audience can experience an emotion that is type-identical with the emotion of a character, and here the cause of the experience is the character's emotion itself. I have suggested that this dynamic may depend on the identification of the audience with the character. On this basis, we should now ask: is it possible for the narrator of the self-narratives considered here to identify with her narrated self?

I have hypothesized that the self-narratives in question contain experiences and events that exceed the person's sense of possibility. That is, these are narratives that depict as possible experiences and events that appear to be precluded to the person due to her existential feelings. As such, it could be argued that any form of identification between the narrator and the narrated self is ruled out. How could someone who feels radically worthless and powerless identify with the protagonist of a story undergoing experiences and events that appear completely unattainable to that person?

It seems indeed unlikely that the person in this example could in any substantial sense 'put herself in the shoes' of the protagonist of this self-narrative. However, provided that something like identification is at all possible with fictional characters, perhaps there could still be the possibility for the person in the example to identify with her narrated self. This may perhaps be the case if the person relates to the narrated scenario not as a potentially real one, but rather as an entirely fictional one. In other words, she may not think that the person in those successful narratives is a realistic version of herself, but she may well see it as an alternative one, a fictional character with whom she just happens to have some features in common. If this is the case and provided, as highlighted above, that identification between audiences and fictional characters is indeed a possibility, then the narrator could still be able to identify with her narrated self. As such-and as argued by the infection model-the narrator could experience certain positive emotions because her narrated self experiences them.

In my previous work (Bortolan 2020b: 200-20I), I suggested that it is possible to relate to one's narrated self as a fictional rather than a real version of oneself, but I acknowledged that emotional identification with the protagonist of one's self-narratives in the cases at issue may be unlikely to take place. However, I am now more open with regard to this possibility. The reason for this is that suspending our belief in the reality of what is being narrated can often enable us to have a range of experiences that we would normally not undergo. For instance, we can experience emotions for fictional characters that we would not experience - or even consider acceptable to experience-for people in real life (Kieran 20I0). 
Thus, as fiction can lift some of the constraints by which we are bound in relating to others, it can also lift some of the constraints that apply to the way in which we relate to ourselves, enabling us to at least pretend that we are the person whose story we are narrating in a certain way.

However, even if emotional identification with her narrated self was precluded, I have suggested (Bortolan 2020b: 202) that the person could still respond to the experiences of her narrated self with coincident emotional states. Recall that, according to Carroll, these are states the audience undergoes as a result of how the circumstances are depicted, and not as a consequence of the experience of the character. This dynamic does not require any form of identification, but rather an emphasis in the narrative on certain emotion-eliciting factors, and this is something to which the individual in our hypothetical example would have access to.

The person would indeed react emotionally to the imagined scenario, not because she identifies with her imagined self, but rather because she reacts to the circumstances in which her imagined self is placed by the narrative. For instance, if she imagines herself giving a successful talk, what may trigger a reaction would be imagining an audience that listens enraptured to her or that responds with an enthusiastic applause and relevant and supportive questions. Here emotional states of excitement, expectation, enthusiasm, and empowerment may emerge, not because the person identifies with herself as a character experiencing such emotions, but rather because these are the types of emotional states that are triggered in such a context. Confidence, optimism, and pride may exude from the situation and not just from the person who lives it.

In addition to this, vectorially converging emotions could also be undergone by the person in this example. In Carroll's characterization, these are emotional states the audience experiences as a response to the emotions of a character, but contrary to what is the case in identification and coincident emotional states, the audience and character's experiences are not type-identical. Vectorially converging emotive states, however, have similar valence, that is, they are both either negative or positive affective states.

This dynamic, too, seems to be within reach for the person who engages with what appears to her as a fictional version of herself and may be even more easily undergone than coincident emotional states or emotional identification. The narrated self in our example is someone whose experiences, behaviors, and achievements exceed the narrator's sense of what is possible for her real self. As such, some of the emotions undergone by the narrated self are beyond the realm of what the narrator perceives herself as capable of attaining. However, even if the narrator was not able to join in with the emotions of her narrated self-namely, to experience emotions that are type-identical to those of the protagonist of her self-narratives-she could still respond with emotions of the same valence. For instance, the self in the story she narrates is successful, confident, and in control of her circumstances, and while she may not be able to share these feelings, she may still feel gladdened or enlivened or relieved by what is recounted, much like what would happen if the protagonist of the story she is engaging with was someone else. A vectorially converging emotion may have lower intensity than the emotion of the narrated self, but in virtue of this, too, it might be easier for the narrator to 
experience it when it is otherwise difficult to take the perspective of the narrated self or to focus fully on the narrated circumstances.

Sympathy and solidarity for one's narrated self also seem to be responses of which the protagonist of the example we are considering would be capable. In Carroll's account, the form of caring for a character that these responses require also does not rest on the identification between the audience and the characters. On the contrary, in these cases, the perspective of the audience and that of the characters may be markedly different. For instance, the former may be responding with a negative emotion when the latter is undergoing a positive one. Having a pro-attitude for a character one does not identify with-and in our set up, for a narrated self that is perceived to be to a degree fictional-again seems to be something within the narrator's affective reach.

At this point, however, one could wonder to what extent those whose sense of possibility is radically restricted might be able to be concerned about what befalls their narrated self. For example, it could be suggested that someone who experiences existential feelings of hopelessness might not perceive herself as worthy enough to warrant the benevolent attitude at the core of sympathy. Once again, though, it is helpful to remember that what is presupposed by my account is the presence of the ability to be minimally concerned with others and, more specifically, fictional characters. If this is present, the engagement with certain self-narratives is the means by which one's own self can become, qua narrated character, the object of one's caring. In addition, it is not necessarily the case that significant restrictions of one's sense of possibility go hand in hand with the loss of ability to care about oneself. One might lose hope that things will ever be different but still be worried that this is the case, experiencing a series of emotions -for example, anxiety or fear-regarding this perceived state of affairs.

Furthermore, independently of whether the person is able to identify with her 'narrated self', she may still be inclined to experience some of her emotions due to mirror reflex mechanisms. This is the case because she may involuntarily imitate, at the personal or subpersonal level, some of the physical manifestations associated with those emotions. Imagining someone, or oneself, laughing in happiness may put a smile on one's face, while imagining someone, or oneself, crying in despair is likely to result in the assumption of a rather somber look.

As Carroll observes (20I I: I79), the bodily responses that are triggered as part of a mirror mechanism are not to be confused with the emotion itself; as such, undergoing them should not be equated with experiencing a full-fledged emotional state. However, these responses may facilitate the experience of the emotion at issue and thus may play a role in the emergence, for instance, of emotional identification and coincident emotional states.

\section{The Power of Narrativity and Enduring Affective Transformations}

These dynamics are closely connected to the role played by the imagination in story-telling, and the effects that this can have on a person's mental and practical life. Catriona Mackenzie (2008), for example, argues that imaginative processes 
and, in particular, 'imaginative projection' are key to narrative thinking and the processes through which we can change our 'practical identities' over time. More specifically, she suggests that by imagining our future selves in the scenarios generated by certain decisions, we can experience and understand how we would feel if certain courses of action were pursued, thus acquiring key information to guide our choices. Mackenzie highlights that this is the case in virtue of certain features of the imagination, and, in particular, of what Richard Wollheim calls 'cogency' (I984: 79).

Wollheim distinguishes between two forms of imagining-i.e., imagining centrally and acentrally (I984: 74ff.) -and claims that both have the power to shape the person's affective and cognitive experience although to different degrees. When I centrally imagine something, I do it from the point of view of one of the characters in the imagined scene (Wollheim I984: 74; Mackenzie 2008: I 24). The character whose point of view I take could be either myself-if I am one of the people who feature in the imagined scene-or someone else, but the key feature of imagining centrally is that there is an individual perspective that is represented in the scene. When imagining acentrally, on the other hand, the scene is not imagined from the point of view of any of the characters in it.

Wollheim observes that cogency is a property of central imagining, and he describes it in the following terms:

As I centrally imagine the protagonist's thinking, experiencing, feeling this or that, so I shall tend to find myself in the condition-cognitive, conative, affective-in which the mental states that I imagine, were I actually to have them, would leave me. (I984: 79-80)

What is described here by Wollheim is consonant with what I illustrated previously with regard to cases of emotional identification when I suggested that these are cases in which the audience and the character experience the same emotion due to the former taking the perspective of the latter. According to Wollheim, however, imagination can give rise to certain affects also when imagining acentrally (I984: 80 ), provided that the audience is affectively responsive to the characters. In these circumstances, too, the audience may be left in a 'residual' affective condition, namely, the one audience members would have experienced had they been present at the imagined event with the same sympathetic attitude they took during the imaginative act (I984: 8O-8I). This is an insight that is of particular relevance for the investigation of forms of affective relation between audiences and characters that do not require identification.

Imagining acentrally is a form of non-perspectival imagining, and as such, it does not rely on the person's capacity to put herself in the shoes of any of the characters, thus being a form of experience that could be undergone also by those who cannot identify with the characters. As I have argued, this could be the case with self-narratives where the narrator may not be able or willing to identify with her narrated self. However, by acentrally imagining the narrated situation, the narrator could still experience-in relation to their narrated self-emotions that 
are coincident or vectorially converging and could also be able to experience sympathy, solidarity, and reflexive mechanisms.

The idea that engaging in activities like imagining and story-telling can have a positive and transformational impact on one's affective experience is consonant also with some core tenets of cognitive therapy (CT) and cognitive-behavioral therapy (CBT) (see, e.g., Beck and Alford 2009; Lewinsohn et al. I992). These psychotherapeutic approaches are based on the idea that certain modifications of one's cognitive processes can lead to emotional changes that are health-enhancing. Action-related dynamics are also central to these processes-in particular in CBT -because what is considered to play a therapeutic role is not only the modification of one's thoughts, but also the challenging of dysfunctional thoughts through the implementation of certain behaviors (Hollon and Beck 2013).

Engaging with particular self-narratives can be relevant in this context as narratives provide us with models of thought and action and, more specifically, thought and action associated with emotions (cf. Hogan 20II). Stories often involve depictions of the reasons that lead characters to act in certain ways, and emotions are very powerful motivational factors (cf. Hogan 20II). In addition, emotions themselves are often the focus of stories because it is the affectively significant events and situations that tend to be narrated (Hardcastle 2003: 354). Through stories we thus get a portrayal of what the experience of certain emotions typically looks like, and this includes the behaviors that people tend to display when experiencing those emotions. Stories provide us with 'templates for action and action-sequences' (Herman 20I3: 246), and this is the case also for actions that are integral or connected to emotions.

This is relevant to the case of psychiatric illness as the restriction of one's sense of possibility and the range of affective experiences one is likely to undergo may diminish the familiarity with the patterns of behavior that may ensue from the experience of certain emotions. If I am used to feeling powerless, the ways of behaving that are associated with confidence and empowerment will be (or become) something that I am less acquainted with-they will not come natural to me, either in thought or action. A story that shows me how one usually behaves when feeling confident or empowered will thus provide me with models I can imitate, and as a result, not only can certain emotions be more easily triggered, but these can be followed by further consistent actions and thoughts.

In other terms, engaging in story-telling that involves the narration of positive emotions may provide the narrator with examples of how that emotion can be enacted or acted upon. This can make it easier for the narrator to act and think in ways that are consistent with those positive emotions, thus bringing about the affective transformations that, as highlighted by cognitive and cognitive-behavioral frameworks, are facilitated by the modification of certain thoughts and the performance of certain actions.

These dynamics are clearly illustrated by some first-personal reports of patients suffering from depression to the treatment of which both narrative and cognitive-behavioral approaches have been applied (e.g., Angus and Greenberg 20II; Hollon and Beck 20I3). For example, in describing the experiences and practices that were key to her recovery, Tracy Thompson provides an account in 
which the transformational power of both words and actions emerges clearly. As she explains:

[t]he single most valuable tool was the one that sounds the most mindless: rote repetition. . . . When I felt the familiar hollowness in the pit of my stomach, the first prickling of my skin, I would quickly try to come up with a phrase to repeat. It had to be a concrete, positive message, not a nonsense mantra but something that would help me through a bad moment. Sometimes I would write it down, as if I were a student kept after school; other times, I just repeated it to myself.

'Every day, I'm a little bit better.'

'I will have a family someday.'

Over time, I found the most effective way of doing this was to combine the message with some physical action-so that, for instance, walking down the street to work, I could time the words to the sound of my heels on the pavement. ...

The words reinforced the action; the action reinforced the words. Taken together, it was as if a bulldozer were crashing through the under brush of neurons in my brain, creating a new road, obliterating the paths that had been there before. Those old paths had been the automatic negative thoughts-'I am defective' or 'I am not worth loving'. (Thompson I996: 233-34)

A particular self-narrative can provide the framework in which certain thoughts are articulated and certain actions are modeled, thus anchoring the cognitive and behavioral changes that are conducive to more positive emotions. As hinted at previously, this further illuminates why, by responding affectively to narratives that have herself as the main character, a patient may become able to experience emotions previously precluded to her by the presence of certain existential feelings.

However, it may be observed that occasionally experiencing an emotion that is in tension with one's existential feelings is not enough to lead to a transformation of these feelings and, relatedly, of the person's sense of possibility. Even admitting that in the midst of existential feelings of hopelessness one may be able to see some light, it is very uncertain that this experience could even scratch the surface of the background affects with which it is in tension.

This cautionary consideration correctly draws attention to the fact that change, in the circumstances that we are examining, is a complex and lengthy process, and a careful exploration of its various aspects should be developed. Nevertheless, the phenomenological accounts from which this analysis has moved are explicit in suggesting that the experience of a single intentional state can 'act upon' (Ratcliffe 20I5: I 5I) or 'sink back. . . into' (Strasser I977: I87) the moods or existential feelings in its background, thus highlighting its transformative potential. I believe that the best way to interpret this idea is to claim that the intentional state does not bring about the transformation by itself, but rather constitutes a first step in a process that can lead to a lasting change of moods or existential feelings. This, I think, is the case for multiple reasons. 
The first has to do with the influence that the emotions triggered by certain self-narratives may have on future affective reactions. According to Hogan (20II: 240), for example, '[a]ny strong emotion episode is likely to be stored as an emotional memory' and to influence responses in future situations. It may be easier to experience emotions we are familiar with, and a recent occurrence of a positive affective response may facilitate the experience of analogous responses in the future.

This dynamic reflects an aspect of the relationship between language and affectivity more broadly and has been investigated by Colombetti (2009) with reference specifically to the impact that emotion labels and classifications can have on the structure of the affects themselves. Colombetti suggests that linguistic expression enables us to 'condense' complex experiences in simpler terms, thus making them more 'accessible' (2009). Through linguistic labelling and description some emotional experiences can thus acquire more visibility, and this, according to Colombetti, makes it easier for people to be aware of their existence and to undergo them. By virtue of their being narrated, certain emotions may thus become more salient for the person, and experiencing those emotions may then be a more a concrete possibility.

A further insight relevant in this context comes from the investigation of the role of narrative and imaginative thinking in the development of character traits, including virtues. For example, Goldie (20I2: 9Iff.) argues that imagining ourselves or others in certain situations-which, in this context, involves imagining the emotions that we or others would experience in said situations and/or undergoing an emotion as a response to what we are imagining (92-93) - can shape our dispositions to feel and act in certain ways. This draws attention to how, gradually and through practice, certain responses can become automatic, thus making the imaginative effort no longer necessary. Similarly, the transformative power of emotions that are in tension with one's background affects may be dependent upon their repetition and the progressive formation of new dispositions to think, be emoted, and act in ways that are at odds with existing background affective orientations, ultimately leading to the latter being overcome.

\section{Conclusion}

This study has explored how one's sense of possibility and the existential feelings in which it is anchored can be modified by the engagement with certain self-narratives. More specifically, I have argued that, provided that one has maintained the capacity to respond affectively to fictional characters, similar affective responses can be engendered by the engagement with one's narrated self.

I have suggested that while emotional identification with oneself as the protagonist of one's self-narratives may not always be achievable, certain selfnarratives can trigger the experience of emotions that are 'coincident' or 'vectorially converging' to the emotions of the narrated self, toward whom emotions rooted in sympathy, solidarity, and mirror reflexes can also be experienced. Through these dynamics the narrator can come to undergo emotions the experience of which is made unlikely by the presence of certain background 
feelings, and I have shed light on the factors-including imagination and the influence of narratives on behavior-that make this possible.

ANNA BORTOLAN

SWANSEA UNIVERSITY

anna.bortolan@swansea.ac.uk

\section{References}

Angus, Lynne E., and Leslie S. Greenberg. (20II) Working with Narrative in Emotion-Focused Therapy: Changing Stories, Healing Lives. Washington DC: American Psychological Association.

Beck, Aaron T., and Brad A. Alford. (2009) Depression: Causes and Treatment. 2nd ed. Philadelphia: University of Pennsylvania Press.

Bortolan, Anna. (2017) 'Affectivity and Narrativity in Depression: A Phenomenological Study'. Medicine, Health Care and Philosophy, 20, 77-88.

Bortolan, Anna. (2020a) 'Narratively Shaped Emotions: The Case of Borderline Personality Disorder'. The Journal of Medicine and Philosophy, 45, 2 I 2-30.

Bortolan, Anna. (2020b) 'Overcoming the Gaze: Psychopathology, Affect, and Narrative'. In Anya Daly, Fred Cummins, James Jardine, and Dermot Moran (eds.), Perception and the Inhuman Gaze: Perspectives from Philosophy, Phenomenology, and the Sciences (New York: Routledge), I92-204.

Bruner, Jerome. (2002) Making Stories: Law, Literature, Life. Cambridge, MA: Harvard University Press.

Carroll, Noël. (200I) 'Art, Narrative, and Emotion'. In Noël Carroll, Beyond Aesthetics: Philosophical Essays (Cambridge: Cambridge University Press), 2I 5-35 (reprint).

Carroll, Noël. (20II) 'On Some Affective Relations between Audiences and the Characters in Popular Fictions'. In Amy Coplan and Peter Goldie (eds.), Empathy: Philosophical and Psychological Perspectives (Oxford: Oxford University Press), I62-84.

Colombetti, Giovanna. (2009) 'What Language Does to Feelings'. Journal of Consciousness Studies I 6, 4-26.

Cuddy, Amy. (2012) 'Your Body Language May Shape Who You Are'. TEDGlobal 20 I2 [video]. https://www.ted.com/talks/amy_cuddy_your_body_language_may_shape_who_you_are.

Elpidorou, Andreas, and Lauren Freeman. (20I5) 'Affectivity in Heidegger I: Moods and Emotions in Being and Time'. Philosophy Compass, 10, 66I-7 I.

Fuchs, Thomas. (2007) 'Psychotherapy of the Lived Space: A Phenomenological and Ecological Concept'. American Journal of Psychotherapy, 6I, 423-39.

Gallagher, Shaun, and Dan Zahavi. (2012) The Phenomenological Mind. 2nd ed. New York: Routledge.

Goldie, Peter. (2012) The Mess Inside: Narrative, Emotion, \& The Mind. Oxford: Oxford University Press.

Greenberg, Leslie S., and Lynne E. Angus. (2004) 'The Contributions of Emotion Processes to Narrative Change in Psychotherapy. A Dialectical Constructivist Approach'. In Lynne E. Angus and John McLeod (eds.), The Handbook of Narrative and Psychotherapy. Practice, Theory and Research (Thousand Oaks: Sage Publications), 33 I-49.

Guignon, Charles. (2003) 'Moods in Heidegger's Being and Time'. In Robert C. Solomon (ed.), What is an Emotion? Classic and Contemporary Readings. 2nd ed. (New York: Oxford University Press), I 8 I-90.

Hardcastle, Valerie G. (2003) 'Emotions and Narrative Selves'. Philosophy, Psychiatry, \& Psychology, Io, 353-55.

Heidegger, Martin. (I962) Being and Time. Translated by John Macquarrie and Edward Robinson. New York: Harper \& Row.

Herman, David. (2013) Storytelling and the Sciences of Mind. Cambridge, MA: The MIT Press. 
Hogan, Patrick C. (20II) Affective Narratology: The Emotional Structure of Stories. Lincoln: University of Nebraska Press.

Hollon, Steven D., and Aaron T. Beck. (2013) 'Cognitive and Cognitive-Behavioral Therapies'. In Michael J. Lambert (ed.), Bergin and Garfield's Handbook of Psychotherapy and Behavior Change. 6th ed. (Hoboken: John Wiley \& Sons), 393-442.

Kieran, Matthew. (20I0) 'Emotions, Art, and Immorality'. In Peter Goldie (ed.), The Oxford Handbook of Philosophy of Emotion (Oxford: Oxford University Press), 68 I-703.

Lamarque, Peter. (2004) 'On not Expecting Too Much From Narrative'. Mind \& Language, I9, 393-408.

Lewinsohn, Peter M., Ricardo F. Muñoz, Mary Ann Youngren, and Antonette M. Zeiss. (I992) Control Your Depression. Rev. ed. New York: Simon \& Schuster.

Mackenzie, Catriona. (2008) 'Imagination, Identity, and Self-Transformation'. In Catriona Mackenzie and Kim Atkins (eds.), Practical Identity and Narrative Agency (New York: Routledge), I I-45.

Payne, Martin. (2006) Narrative Therapy: An Introduction for Counsellors. 2nd ed. London: SAGE Publications.

Pickard, Hanna. (2015) 'Stories of Recovery: The Role of Narrative and Hope in Overcoming PTSD and PD'. In John Z. Sadler, Werdie (C.W.) Van Staden, and K.W.M. Fulford (eds.), The Oxford Handbook of Psychiatric Ethics, vol. 2 (Oxford: Oxford University Press), I 3 I 5-27.

Ratcliffe, Matthew. (2005) 'The Feeling of Being'. Journal of Consciousness Studies, I2, 43-60.

Ratcliffe, Matthew. (2008) Feelings of Being: Phenomenology, Psychiatry and the Sense of Reality. Oxford: Oxford University Press.

Ratcliffe, Matthew. (2010) 'Depression, Guilt and Emotional Depth'. Inquiry: An Interdisciplinary Journal of Philosophy, 53, 602-26.

Ratcliffe, Matthew. (20I2) 'The Phenomenology of Existential Feeling'. In Joerg Fingerhut and Sabine Marienberg (eds.), Feelings of Being Alive (Berlin: De Gruyter), 23-53.

Ratcliffe, Matthew. (20I3a) 'What is it to Lose Hope?'. Phenomenology and the Cognitive Sciences, I 2, 597-6I4.

Ratcliffe, Matthew. (2013b) 'Why Mood Matters'. In Mark A. Wrathall (ed.), The Cambridge Companion to Heidegger's Being and Time (New York: Cambridge University Press), I 57-76.

Ratcliffe, Matthew. (201 5) Experiences of Depression: A Study in Phenomenology. Oxford: Oxford University Press.

Ratcliffe, Matthew. (2016) 'Existential Feeling and Narrative'. In Thiemo Breyer and Oliver Müller (eds.), Funktionen des Lebendigen (Berlin: De Gruyter), I69-92.

Schechtman, Marya. (2007) 'Stories, Lives, and Basic Survival: A Refinement and Defense of the Narrative View'. Royal Institute of Philosophy Supplement, 60, I 5 5-78.

Slaby, Jan. (2008) 'Affective Intentionality and the Feeling Body'. Phenomenology and the Cognitive Sciences, 7, 429-44.

Slaby, Jan. (20I2) 'Affective Self-Construal and the Sense of Ability'. Emotion Review, 4, I 5 I-56. Slors, Marc. (I998) 'Two Conceptions of Psychological Continuity'. Philosophical Explorations: An International Journal for the Philosophy of Mind and Action, I, 6I-80.

Strasser, Stephan. (I977) Phenomenology of Feeling: An Essay on the Phenomena of the Heart. Translated by Robert E. Wood. Pittsburgh: Duquesne University Press.

Thompson, Tracy. (1996) The Beast: A Journey Through Depression. New York: Plume.

Wollheim, Richard. (1984) The Thread of Life. Cambridge, MA: Harvard University Press.

Zahavi, Dan. (2005) Subjectivity and Selfhood: Investigating the First-Person Perspective. Cambridge, MA: A Bradford Book, The MIT Press. 